\title{
Study on the Reconsidering and Countermeasures for Deepening Innovation and Entrepreneurship in Universities
}

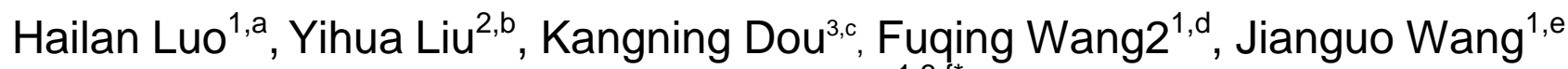 \\ and Fei Wang ${ }^{1,3, \AA^{*}}$ \\ ${ }^{1}$ Luohe Key Laboratory of Medical Bioengineering, Luohe, China \\ ${ }^{2}$ The Second Affiliated Hospital of Luohe Medical College, Luohe, China \\ ${ }^{3}$ Department of Food and Nutrition of Luohe Medical College, Luohe, China \\ axiaohailuo1224@163.com, b lyh-lyh990221@163.com, c779627630@qq.com, \\ dwangfq22000@163.com, ewr0395@sina.com, fwhovering@yahoo.com
}

\begin{abstract}
Keywords: Innovation and entrepreneurship; Philosophy; Mechanism; Practice; Faculty development.
\end{abstract}

\begin{abstract}
Even though China is now strongly encouraging the innovation and entrepreneurship education in universities, it is not dominant which only makes up for the demerits of career development education and is temporary policies to drive employment based on entrepreneurship without reaching a high level and cannot facilitate the development of real economy, acting as a supporting role in society. All of us should enhance the consciousness of innovation and entrepreneurship so as to improve its bump up ratio and vigorously promote its development. Besides, we have to build a sound environment for innovation and entrepreneurship and select role models with promotion to highlight its characteristics and continually encourage the innovation and entrepreneurship education in universities. What's more, we have to reform and create new technologies and apply it into market. Finally, the society can enter the stage that schools cultivate innovation and entrepreneurship, the government assists it, society supports it and universities dare to start up their own business. Based on this, a good social atmosphere can be created that innovation as well as entrepreneurship is able to drive economic development.
\end{abstract}

\section{Introduction}

The Ministry of education as well as the Communist Youth League has proposed clear request for innovation and entrepreneurship for many times. Both the party and the Government attach great importance to innovation and entrepreneurship. In 18th party congress, the government has made important deployment to cultivate innovative and enterprising talents. In these years, universities gradually attach importance to innovation and entrepreneurship education and have achieved great progress. However, there are knotty problems remaining to be solved which ask universities to deepen the reform on innovation and entrepreneurship education in universities.

\section{Reflections on the Existing Problems of Innovation and Entrepreneurship Education in Universities}

\begin{abstract}
How to Distinguish Innovation and Entrepreneurship, Employment and Entrepreneurship from Innovation and Entrepreneurship Education as well as Quality Education? Economist Joseph Schumpeter innovates a theory while explaining the relationship between innovation and entrepreneurship, that is innovation is a new combination of production factors and production conditions, while entrepreneurship includes innovation, techniques that never be tried and establishing new organizations. From this theory, we can see that innovation is fundamental and basis of entrepreneurship, innovation can drive entrepreneurship and entrepreneurship promotes innovation. People who can start up their own business are not necessarily inventors, but they have to find out
\end{abstract}


potential chances with adventurous spirit. Meanwhile, people who can innovate are not necessarily entrepreneurs however the potential value of innovation result is demonstrated via entrepreneurs and they help to transfer into productivity. Therefore, innovation pays more attention to the overall development of individual and different entrepreneurship aims to realize self-worth.

Concerning the relationship between employment and entrepreneurship, entrepreneurship is a higher and better level of employment. Entrepreneurship can promote the development of employment, which cannot only increase the opportunities of employment but also create more jobs. More importantly, entrepreneurship is able to make employment stable while so-called entrepreneurship includes post entrepreneurship and social entrepreneurship. Moreover, entrepreneurship can help people to be engaged in one matter and contribute all efforts to it, which can be beckoned as exam to experience the youth. Furthermore, it can not only make benefits but also improve the social employment and if most of people join in entrepreneurship, they shall do benefit to the society.

In terms of the relationship between innovation as well as entrepreneurship education and quality education, the nature of the former is innovating the knowledge and cultivating the innovation as well as entrepreneurship ability and techniques. To conclude, it can be beckoned as excellent quality education, which aims to cultivate a dazzling array of modern talents who can develop comprehensively and equipped with innovation as well as entrepreneurship spirit.

In universities, the target to develop innovation and entrepreneurship education is same to develop other educations, which aim to cultivate a number of talents with good quality. Quality education is the slogan of this era, and its focus should be which talents are needed by the society. Based on the above we can clearly see that it is the same in essentials while differing in minor points because they both aim to cultivate talents which only differ in terms of talents types as well as focus.

Concerning the Philosophy of Education Aim, How to Make Innovation Spirit, Entrepreneurship Spirit and Innovation as well as Entrepreneurship Ability Become Important Indicators to Cultivate Talents? When we judge whether an individual is equipped with innovation spirit, entrepreneurship spirit and innovation as well as entrepreneurship ability, we are implicitly commenting on him which are evaluation indicators and results of universities' innovation and entrepreneurship education. We have to make these implicit indicators become obvious through innovative competitions etc so as to full play their abilities and make innovation as well as entrepreneurship become the targets of all of human beings.

Concerning Education Value Orientation, How to Judge Different Values of Cultivating Competitors for Employment and Cultivating Creators for Employment? Nowadays, there are still some old ideas, and some domestic universities as well as local career center still takes the employment ratio as a core standard to evaluate whether universities have cultivated excellent talents. This kind of conservative thoughts shall exist for a long time. At present, the situation is grave and people suffer from economic pressure and face higher education popularization. Therefore, more and more jobs are needed to solve the employment problem which shall also exist for a long time and may lead to social problems. The emergence of innovation and entrepreneurship may help to solve this problem even it cannot fundamentally solve it, it can relive it. Facts show that even innovation and entrepreneurship cannot make people directly become elites, while it can change people's ideas and push them to take actions.

Concerning Education Range, How can Innovation and Entrepreneurship Education Implement Classifying Teaching and Make Special Features while Facing all of Students? While carrying out innovation and entrepreneurship education in universities, it is not enough to provide professional courses we have to also cultivate their innovation and entrepreneurship quality. For diverse students, to carry out innovation and entrepreneurship education requires individualized teaching the obvious shall be the difference of arts and sciences. For science and engineering students, universities should encourage students to put their research into business and productivity based on their knowledge. While for arts students the most important idea is to develop innovation as well as 
entrepreneurship philosophy and explore a new way in terms of entrepreneurship to encourage students help each other and start up business.

\section{Deepen University Innovation and Eentrepreneurship Education Reform Measures}

Innovation Awareness Cultivation should be Focused on. Higher Education Act stipulates that the task of higher education is to foster talents with innovative spirit and practical ability, develop science $\&$ technology and culture, and promote the socialist modernization. Students are the main force of contemporary social innovation and entrepreneurship, while schools are good places for students to learn as well as the source of resources and birthplace of talent. Therefore, schools should take the heavy mission to cultivate talents with innovation and entrepreneurship spirit. However, in order to achieve this goal, schools have to focus on students, timely pay attention to market situation and grasp various market opportunities. 18th Party Congress stressed that the ultimate goal of education is to serve the community, while the education of innovation and entrepreneurship can better develop the society and create more wealth to serve the society. Of course, at the same time of carrying out innovation as well as entrepreneurship education, the first is to make students get rid of traditional education and be equipped with creative ideas and entrepreneurship willingness. The effect shall be better if it is done in the freshmen year to help students in terms of entrepreneurship based on their interests and assign teachers to give lectures. The most important point is to introduce entrepreneurship into credit system to further encourage students and dare to start up their own business.

Education Model should be Reformed. While providing entrepreneurship opportunities and giving guidance, schools should also reasonably reform assessment contents and approaches. For these students, they have to focus on their strong analytical and problem solving skills and explore assessment system for non-standard answers. Universities can start from their own perspective to find out the best appropriate and focus on the popularity of innovation and entrepreneurship education as well as the mining of social resources; besides, universities can introduce entrepreneurship into credit system and establish transformation of entrepreneurship and credit; for those who have willingness to start up their own business, universities should encourage them with help for example changing majors and learn other professional knowledge. If there should be conflict between entrepreneurship and schoolwork, universities should properly tackle with these problems and such as extending the time of term in order to create a sound environment for students to start up their own business.

Well Implement School-enterprise Cooperation should be Carried out. School-enterprise cooperation model is not only the tendency for schools to participate in the innovation and entrepreneurship of universities but also an effective approach for universities to implement innovation and entrepreneurship education. In terms of innovation and entrepreneurship education universities pay attention to the theoretical guidance while there are few chances for practicing. Therefore, it is limited to implement this education in schools. In order to make up for this shortage and make students be equipped with not only knowledge but also skills, schools should full play internal enterprise capital, technique, team management to carry put school-enterprise cooperation. Based on this, students with theoretical knowledge can be send to enterprises to participate in the decision making of enterprise project which is not only helpful to carry out project but also value opportunities for students who want to start up their own business.

Education Base should be Positively Established. The implementation of innovation and entrepreneurship education in universities is equipped with strong practicality and therefore, universities have to establish practice base to cultivate students' spirit as well as ability based on practical education which can help them accumulate practice experience and improve their entrepreneurship ability. To begin with, build on-campus innovation and entrepreneurship education base to organically combine quality-oriented education, teaching practice, and graduation thesis design to comprehensively support students to start up their own business. Meanwhile, establish incubation base, set special entrepreneurship fund so as to provide capital assistance. Besides, schools 
can integrate various resources, and establish social communities to promote university students' innovation, training and management. In short, schools have to establish an innovation and entrepreneurship base to provide support in terms of location, practical training, capital and techniques so as to explain relevant government supporting policies, strengthen communication between universities, enterprises and students to recommend mature projects to enterprises and promote its development with proper follow up. Second, establish outside innovation and entrepreneurship education base so as to expand its scope and provide social practice opportunities to help students better understand the society and enterprises. In the premise of not affecting their learning universities, students can encourage students to start up their own business based on their spare time to participate in social entrepreneurship project and strengthen innovation as well as entrepreneurship cultivation.

Entrepreneurship Atmosphere is Required. While carrying out innovation and entrepreneurship education universities should pay attention to establish an open, free and loose environment which can on the one hand reduce their pressure and on the other hand strengthen their innovation awareness and is beneficial to carry out innovation culture. In the course of creating innovation atmosphere, schools have to always pay attention to the innovation awareness creation and then positively organize various on-campus cultural activities so as to make more students to participate in and enhance cultural appeal. In addition, schools should strengthen the guidance of entrepreneurship education activities as well as promotion. Moreover, they can display a video talking about the experience of successful individuals to encourage students and make them have a better knowledge of entrepreneurship with preparation. If it is possible, schools can also invite successful individuals to come to give a lecture which shall greatly enhance students' enthusiasm. Furthermore, relevant supporting policies can be designed to help students in terms of economy and capital so as to encourage them carry out entrepreneurship activities with venture capital and help them go toward a smooth way.

\section{Conclusion}

To conclude, to deepen the innovation as well as entrepreneurship education reform in universities is an arduous task which requires efforts paid by various sectors. Schools should positively take powerful measures to further deepen and implement it.

\section{References}

[1] W. Gao, Reflection and countermeasures to deepen the innovation as well as entrepreneurship education in universities [J].Ideological \& Theoretical Education. 8(2015)92-95.

[2] Y.J. Chen, Research on innovation as well as entrepreneurship education of university students [D]. Hebei Normal University, 2013.

[3] C. Cheng, Research on the entrepreneurship education in universities from the perspective of students [D].Shanghai Normal University, 2011.

[4] T.Z. Wang, J. Yu, X.X. Xiao, Problems and countermeasures for innovation as well as entrepreneurship education in universities-based on the research on universities in Huaihai region [J]. Innovation and entrepreneurship education. 4(2011)83-86.

[5] X.L. Tong, Research on the innovation and entrepreneurship education system of research universities [D].Wuhan University of Technology[D]. Wuhan University of Technology, 2012.

[6] Q.Y. Rong, Entrepreneurship Education in Stanford University's enlightenment to China [D].Jiangnan University, 2014.

[7] Y.C. Sun, Discuss on the problems and solutions for local university innovation and entrepreneurship education [D].Shandong Normal University, 2012. 